\title{
Performance of asphaltene stability predicting models in field environment and development of new stability predicting model (ANJIS)
}

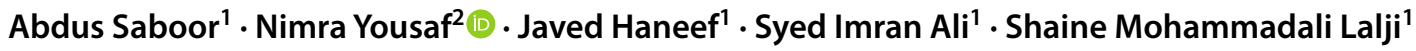

Received: 10 August 2021 / Accepted: 26 November 2021 / Published online: 7 December 2021

(c) The Author(s) 2021

\begin{abstract}
Asphaltene Precipitation is a major issue in both upstream and downstream sectors of the Petroleum Industry. This problem could occur at different locations of the hydrocarbon production system i.e., in the reservoir, wellbore, flowlines network, separation and refining facilities, and during transportation process. Asphaltene precipitation begins due to certain factors which include variation in crude oil composition, changes in pressure and temperature, and electrokinetic effects. Asphaltene deposition may offer severe technical and economic challenges to operating Exploration and Production companies with respect to losses in hydrocarbon production, facilities damages, and costly preventive and treatment solutions. Therefore, asphaltene stability monitoring in crude oils is necessary for the prevention of aggravation of problem related to the asphaltene deposition. This study will discuss the performance of eleven different stability parameters or models already developed by researchers for the monitoring of asphaltene stability in crude oils. These stability parameters include Colloidal Instability Index, Stability Index, Colloidal Stability Index, Chamkalani's stability classifier, Jamaluddin's method, Modified Jamaluddin's method, Stankiewicz plot, QQA plots and SCP plots. The advantage of implementing these stability models is that they utilize less input data as compared to other conventional modeling techniques. Moreover, these stability parameters also provide quick crude oils stability outcomes than expensive experimental methods like Heithaus parameter, Toluene equivalence, spot test, and oil compatibility model. This research study will also evaluate the accuracies of stability parameters by their implementation on different stability known crude oil samples present in the published literature. The drawbacks and limitations associated with these applied stability parameters will also be presented and discussed in detail. This research found that CSI performed best as compared to other SARA based stability predicting models. However, considering the limitation of CSI and other predictors, a new predictor, namely ANJIS (Abdus, Nimra, Javed, Imran \& Shaine) Asphaltene stability predicting model is proposed. ANJIS when used on oil sample of different conditions show reasonable accuracy. The study helps Petroleum companies, both upstream and downstream sector, to determine the best possible SARA based parameter and its associated risk used for the screening of asphaltene stability in crude oils.
\end{abstract}

Keywords Asphaltene $\cdot$ SARA $\cdot$ Stability $\cdot$ Precipitation $\cdot$ ANJIS $\cdot$ Prediction

\section{Introduction}

Nimra Yousaf

nimra_yousaf@yahoo.com

Syed Imran Ali

engrimran@neduet.edu.pk

1 Department of Petroleum Engineering, NED University of Engineering \& Technology, Karachi, Pakistan

2 Oil and Gas Regulatory Authority (OGRA), Karachi, Pakistan
Crude oil contributes a considerable portion to the energy demand of the world (Alimohammadi et al. 2019). Fulfilment of this energy requirement through sustainable production of crude oil is highly important and essential for each country to meet its demand for economic progress. However, under certain circumstances, assurance of required rate of crude oil production demand becomes extremely difficult or nearly impossible due to the solid deposit blockages arising in production flow lines or even in hydrocarbon reservoir. This interruption of hydrocarbon production could be

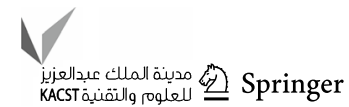


occurred due to the formation of hydrates, emulsions, inorganic scales and organic deposits (Mansoori 2010). Among these above-mentioned solids, asphaltene is regarded to be the most troublesome organic solid deposit because it possesses complex formation phenomenon and therefore requires complicated, diverse and expensive treatment solutions (Melendez-Alvarez et al. 2016; Al-Qasim et al. 2018; Thou et al. 2002).

Initially, the word "Asphaltene" was introduced by a person having name "Boussingault" (1837). According to the widely accepted definition, Asphaltene is the fraction of crude oil which exhibits insolubility in n-alkanes particularly n-pentane and n-heptane, whereas it becomes highly miscible in aromatic compounds such as toluene, benzene, xylene. (Goual 2012). Compositionally, asphaltene molecule possesses high percentage of carbon and hydrogen elements which are present in the form of alkyl chains and aromatic rings along with the presence of small proportion of heteroatoms and metallic elements (Zheng et al. 2020). The molecular weight of asphaltene is not fixed, and researchers have reported a wide range of asphaltene molecular weight because asphaltene molecules undergo in the selfassociation phenomenon which depends upon its polarity, thus causing it to grow in size and ultimately increase the molecular weight (Zheng et al. 2020). However, the most accepted value is $750 \mathrm{~g} / \mathrm{mol}$ (Alimohammadi et al. 2019). Lastly, structure wise; Continental, Archipelago, and YenMullins model are the most popular and accepted structural asphaltene models. Figure 1a-c illustrates the structural models of asphaltene (Fakher et al. 2020).

According to several researchers, there are four governing factors which play a vital role in the precipitation of asphaltene from crude oil. These include the changes in oil composition, variation in temperature and pressure, and electrokinetic effect (Gharbi et al. 2017). Though, alterations in oil composition occur through depressurization process and blending of oils; however, during production of hydrocarbon, the changes in pressure is considered to be the foremost factors among all other affecting factors. The deposition problem could cause emergence of numerous challenges to operators in the form of pore throats clogging in reservoir, wettability alteration of reservoir rock from water wet to oil wet, increase in the oil viscosity, wells, downhole and surface equipment and facilities choking or blocking; thus, causing net hydrocarbon recovery reduction and requirement of the deployment of expensive treatment methods for mitigation (Alimohammadi et al. 2019; Gharbi et al. 2017; Madhi et al. 2018). These treatment techniques may include Chemical, Mechanical, Thermal, Biological, and Ultrasonic methods
Fig. 1 a Archipelago asphaltene structure, b Continental asphaltene structure, and $\mathbf{c}$ Yen-Mullins asphaltene model (Reprint with permission from (Fakher et al. 2020) copyright ${ }^{{ }^{\circ}} 2020$ Springer) (a)

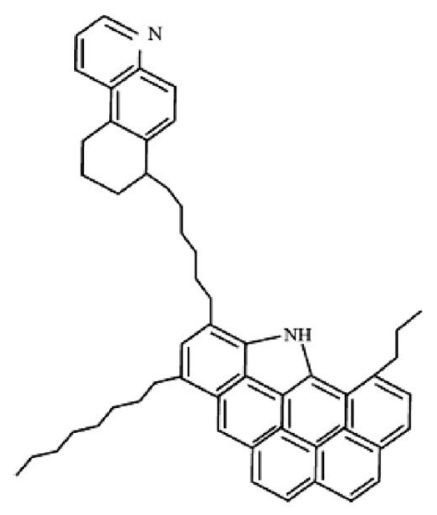

(c)

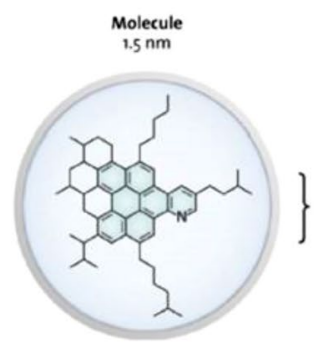

Light Oil: Asphaltene concentration is low. Isolated Molecules

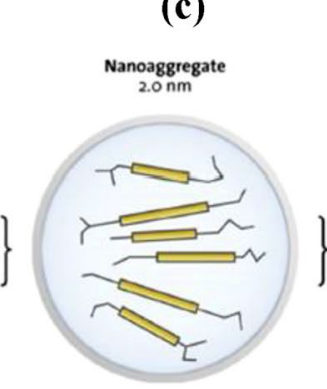

Black Oil: Asphaltene concentration is moderate Nanoaggregates (b)
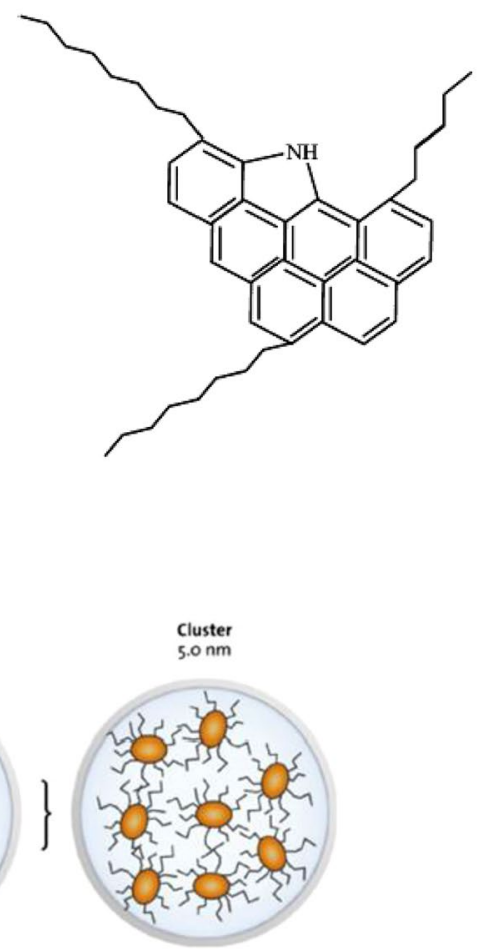

Heavy Oil: Asphaltene concentration is high. Aggregated Clusters 
(Alimohammadi et al. 2019; Gharbi et al. 2017). Among all these mentioned methods, mechanical and chemical approaches are mostly employed.

Looking at the gravity of this asphaltene deposition problem, operating companies usually prefer prevention over mitigation of this issue, as it facilitates them to save treatment related money and expenditures because of the uninterrupted supply of hydrocarbon throughout the life of well. There are various prevention strategies that were reported over the years. Among all of them, SARA based relationships models (Saturates, Aromatics, Resins, Asphaltenes) are quite popular and common (Mohammed et al. 2021; Guzmán et al. 2017; Ali et al. 2021a). These relationships are developed based on the fact that crude oil is characterized on the basis of SARA fractions and each fraction affects the asphaltene stability in crude oil (Ali et al. 2021a). Resins and aromatics promote asphaltene stability in oils, thus ceasing asphaltene precipitation (Ashoori et al. 2017). The reason is because aromatics dissolve asphaltene molecules, while resins are polar components which interact with asphaltene molecules to provide shielding effect against other asphaltene molecules preventing their flocculation (Mansoori 2010; Ali et al. 2021a, b; Ashoori et al. 2017). Alternatively, saturates and asphaltenes component of crude oil favor asphaltene precipitation mechanism. The resins are miscible in saturates thus high saturate contents dissolve more resins letting asphaltene molecules free to combine and deposit (Ashoori et al. 2017). As far as asphaltene contents of crude oil are concerned, although, higher proportion of asphaltene facilitates asphaltene precipitation, but in past there have been some cases reported where crude oils were seen to exhibit unstable behavior even having very low contents of asphaltene (Mansoori 2010; Law et al. 2019).

In past, several investigators have reported different SARA based asphaltene stability predicting models. These models include Colloidal Instability Index, Stability Index, Colloidal Stability Index, Chamkalani's stability classifier, Jamaluddin's method, Modified Jamaluddin's method, Stankiewicz plot, Qualitative-quantitative analysis (QQA) and Stability cross plot (SCP) (Mohammed et al. 2021; Guzmán et al. 2017; Ali et al. 2021a). In this research study, these aforementioned stability predicting models are applied onto the seventeen (17) crude oils SARA datasets having known information about their stability status according to the oil field experience as present in the open literature. Detailed performance analysis, both qualitative and quantitative, of the stability results obtained by each model is carried out to evaluate the models accuracy. Finally, the advantages and limitations or drawbacks of each model found in this study are discussed and accordingly new reliable predicting model is also presented.

\section{Asphaltene stability predicting models}

\section{Colloidal instability index (CII)}

Colloidal Instability Index (CII) assumes crude oil system as colloidal solution which is composed of SARA pseudocomponents. Mathematically, it can be expressed as the ratio of the sum of saturates and asphaltenes contents to the sum of resins and aromatics contents. CII can be calculated using Eq. (1): (Mohammed et al. 2021; Guzmán et al. 2017; Ali et al. 2021a)

$\mathrm{CII}=\frac{(\text { Saturates in } \mathrm{wt} \%)+(\text { Asphaltenes in } \mathrm{wt} \%)}{(\text { Resins in } \mathrm{wt} \%)+(\text { Aromatics in } \mathrm{wt} \%)}$

Following are the stability judgment criteria to determine the crude oils stability: (Mohammed et al. 2021; Guzmán et al. 2017).

For value of $\mathrm{CII} \geq 0.9$, the crude oil is termed unstable, while for the value of $\mathrm{CII} \leq 0.9$, the crude oil is considered as stable. If CII value lies in between 0.7 and 0.9 , then crude oil comes under uncertain zone.

\section{Stability index (SI)}

Stability index (SI) is a well-renowned stability parameter used to find asphaltene stability in crude oil samples. It is expressed as the ratio of asphaltenes to resins (A/R). To determine stability status, if SI value obtained is lower than 0.35 , then crude oil is regarded as stable otherwise unstable. (Mohammed et al. 2021; Guzmán et al. 2017).

\section{Colloidal stability index (CSI)}

CSI index was proposed on the concept that the asphaltene contents present in unstable crude oils are likely to be more polar than those contained by stable oils. CSI can be computed by using Eq. (2): (Mohammed et al. 2021; Guzmán et al. 2017)

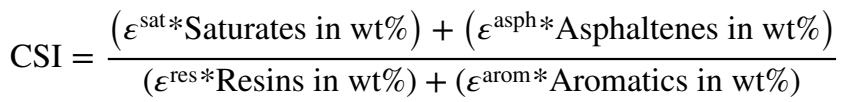

where $(\varepsilon)$ represents a dielectric constant and its values for SARA components for stable and unstable oils are following (Goual and Firoozabadi 2002; Hascakir 2017): Stable crude oils $\left(\varepsilon^{\mathrm{sat}}=1.921, \varepsilon^{\mathrm{asph}}=5.5, \varepsilon^{\mathrm{res}}=4.7\right.$, and $\left.\varepsilon^{\mathrm{arom}}=2.379\right)$. Unstable crude oils $\left(\varepsilon^{\text {sat }}=1.921, \varepsilon^{\text {asph }}=18.4, \varepsilon^{\text {res }}=3.8\right.$, and $\varepsilon^{\text {arom }}=2.379$ ). If CSI comes greater than 0.95 , then oil is considered as unstable else it is categorized as stable (Ali et al. 2021a; Fan et al. 2002). 


\section{Stankiewicz plot (SP)}

Stankiewicz et al. (2002) proposed a plot between ratios of saturates to aromatics and asphaltenes to resins for predicting the asphaltene precipitation risk. Figure 2 shows the Stankiewicz plot which includes a curve separating unstable and stable region (Pereira et al. 2017).

\section{Chamkalani stability classifier (CSC)}

Chamkalani (2015) developed a stability classifier plot by applying technique called "Least square support vector machine (LS-SVM)" for the prediction of asphaltene precipitation in crude oils. Chamkalani stability classifier divided into three zones, namely: severe, mild and minor problem.

\section{Jamaluddin method (Jamal)}

Pereira et al. (2017) and Zendehboudi et al. (2014) also developed a graphical plot using Jamaluddin's experimental data for the prediction of asphaltene stability crude oils. Figure 3 shows the Jamaluddin's plot between asphaltene and resins weight percentage. This plot is split into two regions, namely stable and unstable regions.

\section{Modified Jamaluddin's method (M Jamal)}

Pereira et al. (2017) conducted modification in Jamaluddin's plot to improve its accuracy. The improvement is implemented by decreasing the slope of the line dividing stable and unstable zone. Figure 4 shows the modified Jamaluddin plot.

\section{Sepúlveda stability criterion (QQA: qualitative-quantitative analysis)}

Sepúlveda et al. (Guzmán et al. 2017; Sepúlveda et al. 2010) conducted a Qualitative-Quantitative Analysis for various

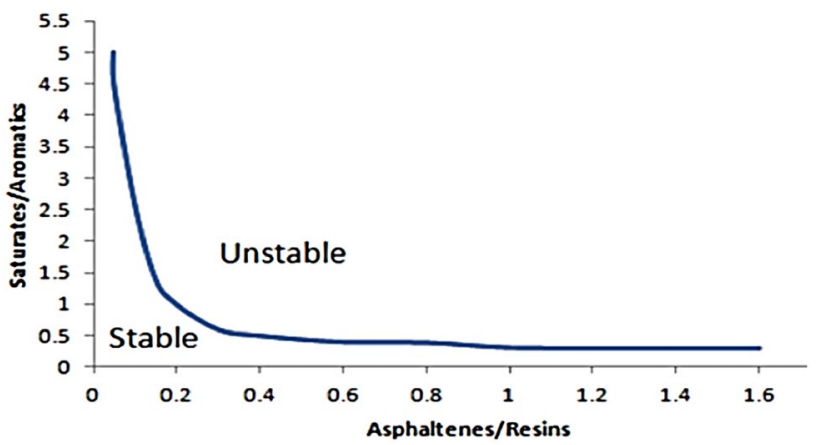

Fig. 2 Stankiewicz plot (Reprinted with permission from (Pereira et al. 2017), Copyright ${ }^{\circledR}$ (2017) American Chemical Society)

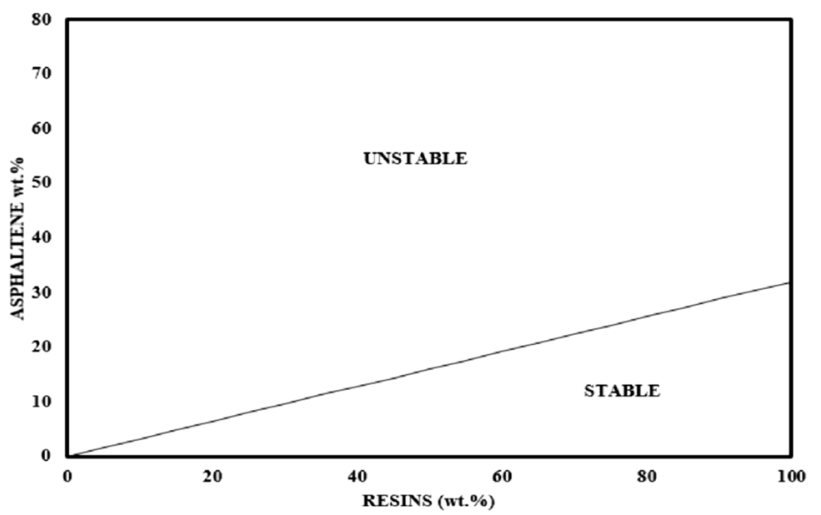

Fig. 3 Jamaluddin's plot (Adapted with permission from (Pereira et al. 2017), Copyright ${ }^{\odot}$ (2017) American Chemical Society)

SARA values relationships which includes: S/A, R/A, (S/ Ar*A), Ar/(S/A), Ar/A and (R/A)/(S/Ar). Finally, they were able to propose different plots for each relationship divided into three regions (unstable, metastable and stable) having assigned numerical values for each region. Figure 5 shows an example of (R/A) case. The maximum value was identified for each SARA relationship and then utilized in further calculations. The dotted line separating the two zones i.e., stable and metastable zones is established by dividing the maximum value obtained by numerical value 2 , whereas the dotted line separating metastable and unstable zone is constructed by the division of maximum value by numerical value 4 for that particular relationship. These three aforementioned zones are assigned a value of 1 (for unstable region), 5 (for metastable region) and 10 (for stable region). Oppositely, for $[\mathrm{Ar} / \mathrm{S} / \mathrm{A})]$ relationship case the interpretation of plot becomes reverse and bottom region of the chart is assigned a value of 10 , for middle region a value of 5 is

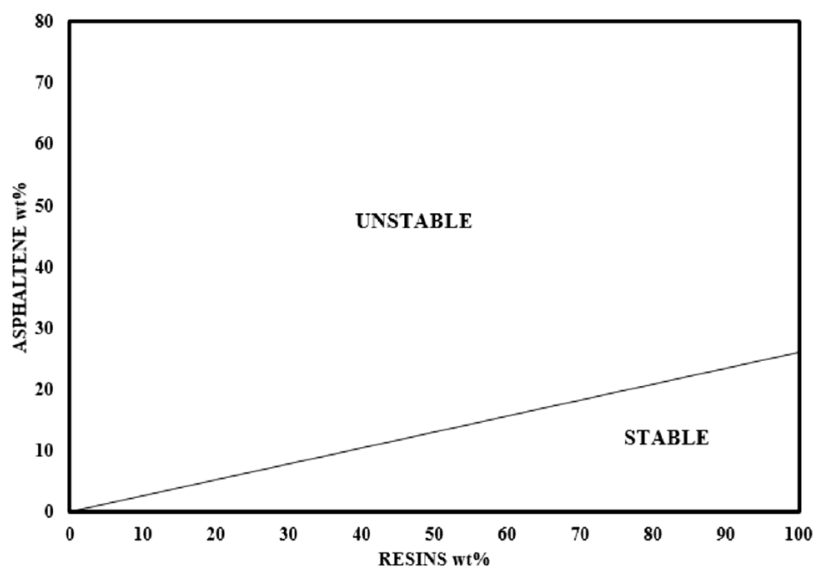

Fig. 4 Modified Jamaluddin's plot (Adapted with permission from (Pereira et al. 2017), Copyright ${ }^{\circledR}$ (2017) American Chemical Society) 
Fig. 5 Example of R/A case (QQA: qualitative-quantitative analysis) (Reprinted with permission from (Guzmán et al. 2017), Copyright ${ }^{\circledR}(2017)$ Elsevier)

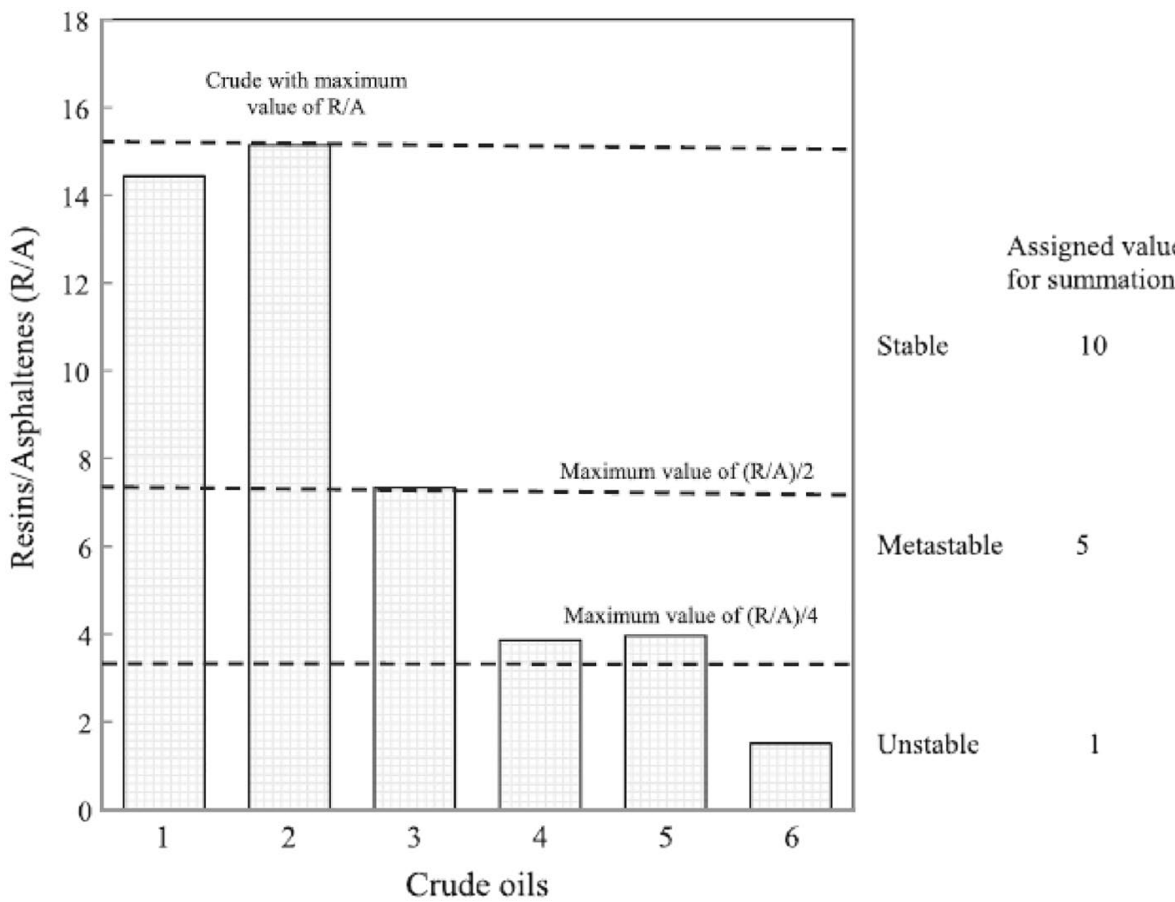

placed and for the upper region the value of 1 is assigned. In addition, these assigned values are added for each SARA relationship discussed and is determined for all crude oil samples studied.

Following rule is to be applied for predicting the asphaltene stability in crude oils (Guzmán et al. 2017; Sepúlveda et al. 2010):

If summation result obtained is found to be greater than 30 , then that particular crude oil will be considered as stable, if summation result is found to be between 15 and 30, then that crude oil will be termed as metastable, and if summation value obtained is found under 15 , then crude oil will be regarded as unstable oil.

\section{Sepúlveda stability criterion (SCP: stability cross plot)}

Sepúlveda et al. (Guzmán et al. 2017; Sepúlveda et al. 2010) also proposed four SARA based stability cross plots as shown in Fig. 6. Unstable and stable zones are also marked on each cross plot through separating curve. These plots can identify crude oil stability status in terms of asphaltene precipitation risk.

\section{Performance metrics}

\section{Accuracy (ACC)}

The most commonly used metric to evaluate the performance of predicting model is accuracy. It is defined as the ratio of total correct predictions to the total number of predictions made. Accuracy (can be expressed mathematically as Eq. (3): (Ali et al. 2021b; Bekkar et al. 2013)]

$\mathrm{ACC}=\frac{\mathrm{TP}+\mathrm{TN}}{\mathrm{TP}+\mathrm{TN}+\mathrm{FN}+\mathrm{FP}}$

\section{Sensitivity (TPR) and specificity (TNR)}

Predictor sensitivity is also known as true positive rate (TPR), recall or hit rate. It indicates the correctly classified stable samples out of total number of stable samples. It can be computed using Eq. (4): (Ali et al. 2021b; Bekkar et al. 2013)

$\mathrm{TPR}=\frac{\mathrm{TP}}{\mathrm{TP}+\mathrm{FN}}$

Similarly, specificity expresses the correctly identified unstable samples out of total number of unstable samples present. It can be calculated using Eq. (5): (Ali et al. 2021b; Bekkar et al. 2013)

$\mathrm{TNR}=\frac{\mathrm{TN}}{\mathrm{FP}+\mathrm{TN}}$

Specificity is also commonly known as true negative rate (TNR) or inverse call. TPR and TNR values close or equal to numerical value 1 indicates good performance of predicting model. 
Fig. 6 Stability Cross Plots for SCP (Reprinted with permission from (Guzmán et al. 2017), Copyright $^{\circledR}$ (2017) Elsevier)
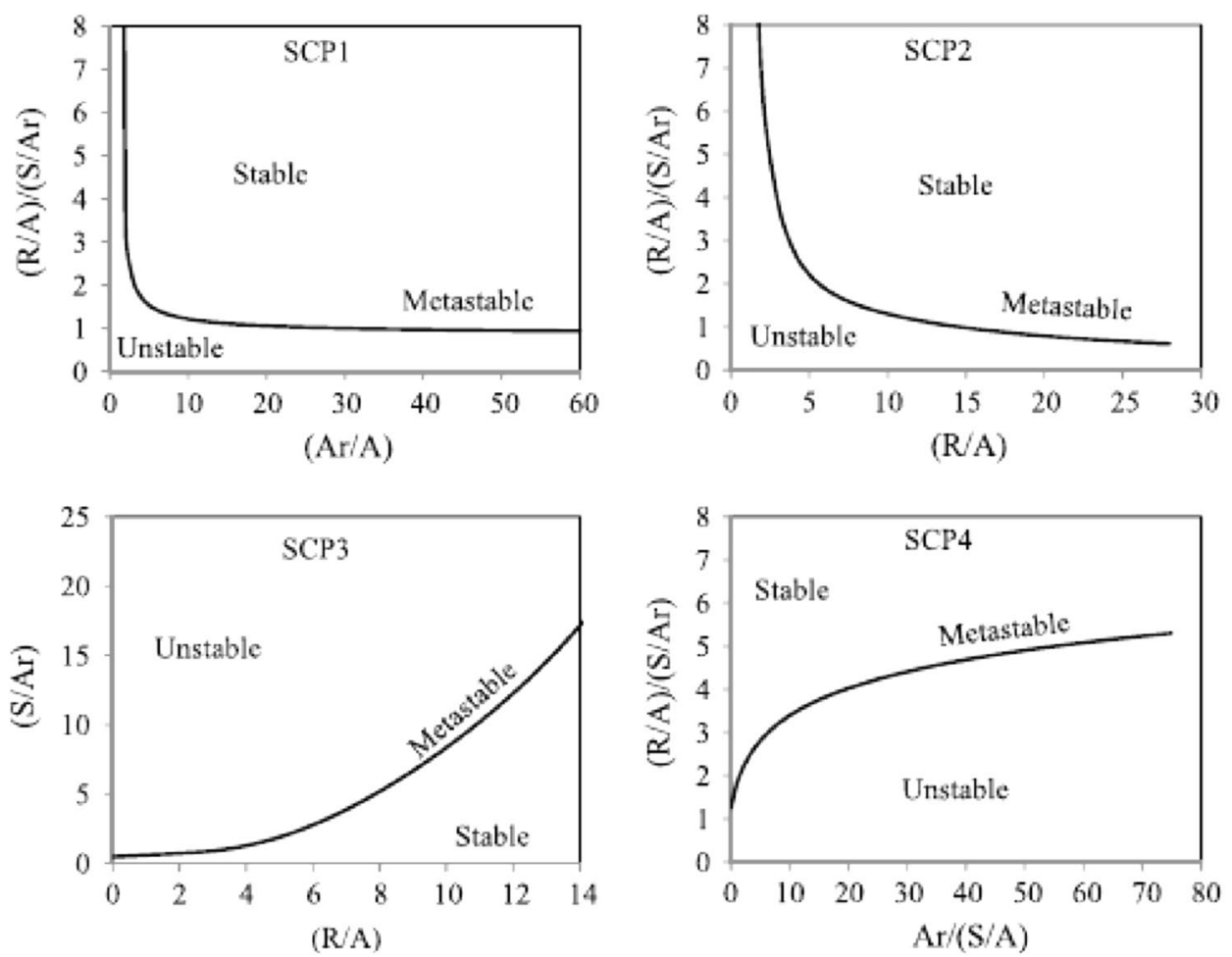

\section{Predictive values (PPV and NPV)}

Predictive value shows predicting model performance with respect to its ability to correctly predict both stable and unstable oil samples. On the other hand, Precision or positive predictive value (PPV) of a predicting model can be expressed as the ratio of the correctly predicted stable samples to the total number of stable samples used. Equation (6) is used to calculate Predictive value (PPV): (Ali et al. 2021b; Bekkar et al. 2013)

$\mathrm{PPV}=\frac{\mathrm{TP}}{\mathrm{FP}+\mathrm{TP}}$

Negative predictive value (NPV) or inverse precision is defined as the ratio of the number of correctly predicted unstable samples by the model to the total number of unstable samples predicted. NPV can be computed using Eq. (7): (Ali et al. 2021b; Bekkar et al. 2013)

$\mathrm{NPV}=\frac{\mathrm{TN}}{\mathrm{FN}+\mathrm{TN}}$

Values of PPV or NPV near to numerical value of 1 indicate high accuracy of predicting model.

Where TP, TN, FP, and FN in the above-mentioned predicting models formula represent the following (Ali et al. 2021b; Bekkar et al. 2013):
$\mathrm{TP}=$ Total number of operationally stable samples correctly predicted by applied predicting model.

$\mathrm{TN}=$ Total number of operationally unstable samples correctly predicted by applied predicting model.

$\mathrm{FP}=$ Total number of operationally unstable samples incorrectly predicted by applied predicting model.

$\mathrm{FN}=$ Total number of operationally stable samples incorrectly predicted by applied predicting model.

\section{Data gathering}

For evaluating the accuracy of applied predicting models, seventeen (17) crude oil samples SARA data having known asphaltene stability status information under field conditions are taken from three different published research papers (Rogel et al. 2001; Leon et al. 2002; Wattana et al. 2005). In this research study, approximately equal number of stable (S) (08) and unstable (U) (09) crude oil samples are used so that asphaltene predicting models overall accuracy cannot be affected by the imbalanced class distribution of applied SARA dataset. Figure 7 is showing the crude oils data used in this study: 
Fig. 7 SARA data of Crude oils and their asphaltene stability operational experience

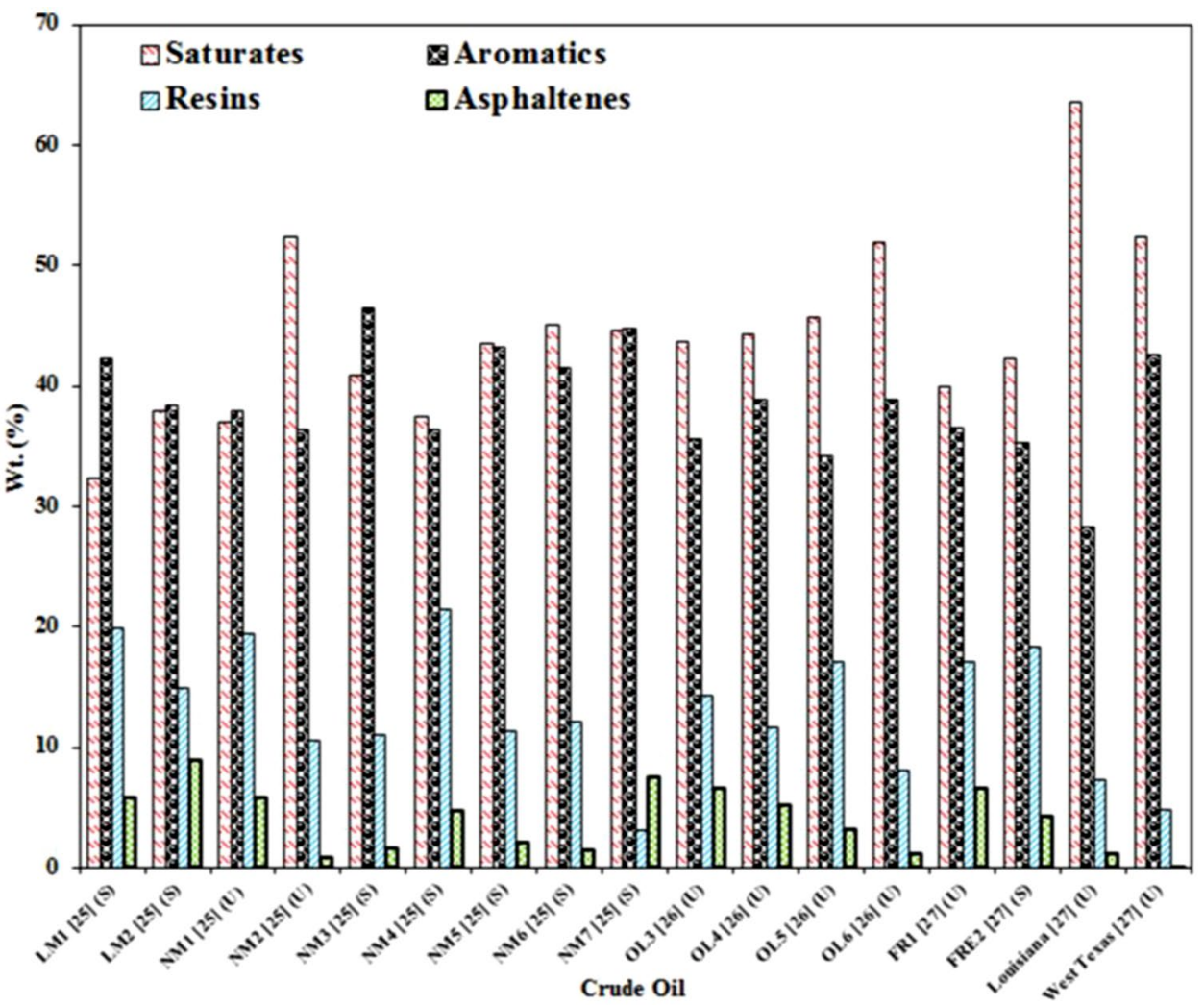

\section{Results and discussion}

Table 1 and Fig. 8 show the results obtained for different asphaltene predicting models when applied to seventeen crude oils SARA data used in this study.

Table 2 shows the stability predicting outcomes of nine predicting models. These results are obtained using calculated values presented in Table 1 and Fig. 8. According to Table 2, CII and CSC models yield same results. Most

Table 1 Calculated values of different SARA relationships

\begin{tabular}{lcccccccccccccc}
\hline Crude Oil & CII & CSI & S/Ar & R/As & As/R & Ar/As & \multicolumn{1}{c}{ S/As } & Ar/(S/As) & (S/Ar*As) & (R/As)/(S/Ar) & Ar/(S/As) & As + S & Ar+R \\
\hline LM1 & 0.61 & 0.49 & 0.77 & 3.41 & 0.29 & 7.28 & 5.57 & 7.58 & 0.13 & 4.46 & 7.58 & 38.10 & 62.00 \\
LM2 & 0.88 & 0.76 & 0.99 & 1.67 & 0.60 & 4.30 & 4.26 & 8.99 & 0.11 & 1.69 & 8.99 & 46.80 & 53.20 \\
NM1 & 0.75 & 1.08 & 0.97 & 3.34 & 0.30 & 6.53 & 6.36 & 5.96 & 0.17 & 3.44 & 5.96 & 42.70 & 57.30 \\
NM2 & 1.14 & 0.91 & 1.44 & 13.13 & 0.08 & 45.38 & 65.50 & 0.55 & 1.80 & 9.09 & 0.55 & 53.20 & 46.80 \\
NM3 & 0.74 & 0.54 & 0.88 & 6.88 & 0.15 & 29.06 & 25.56 & 1.82 & 0.55 & 7.82 & 1.82 & 42.50 & 57.50 \\
NM4 & 0.73 & 0.52 & 1.03 & 4.55 & 0.22 & 7.74 & 7.98 & 4.56 & 0.22 & 4.42 & 4.56 & 42.20 & 57.80 \\
NM5 & 0.83 & 0.61 & 1.01 & 5.65 & 0.18 & 21.60 & 21.75 & 1.99 & 0.50 & 5.61 & 1.99 & 45.50 & 54.50 \\
NM6 & 0.87 & 0.61 & 1.09 & 8.07 & 0.12 & 27.60 & 30.00 & 1.38 & 0.72 & 7.42 & 1.38 & 46.50 & 53.50 \\
NM7 & 1.09 & 1.05 & 1.00 & 0.41 & 2.42 & 5.97 & 5.95 & 7.53 & 0.13 & 0.42 & 7.53 & 52.10 & 47.90 \\
OL3 & 1.01 & 1.48 & 1.23 & 2.17 & 0.46 & 5.38 & 6.61 & 5.37 & 0.19 & 1.76 & 5.37 & 50.20 & 49.80 \\
OL4 & 0.98 & 1.32 & 1.14 & 2.23 & 0.45 & 7.48 & 8.52 & 4.57 & 0.22 & 1.96 & 4.57 & 49.50 & 50.50 \\
OL5 & 0.95 & 1.00 & 1.33 & 5.31 & 0.19 & 10.69 & 14.25 & 2.40 & 0.42 & 3.98 & 2.40 & 48.80 & 51.20 \\
OL6 & 1.13 & 0.97 & 1.33 & 7.36 & 0.14 & 35.36 & 47.18 & 0.82 & 1.21 & 5.52 & 0.82 & 53.00 & 47.00 \\
FR1 & 0.87 & 1.29 & 1.09 & 2.63 & 0.38 & 5.62 & 6.14 & 5.95 & 0.17 & 2.41 & 5.95 & 46.40 & 53.60 \\
FRE2 & 0.87 & 0.62 & 1.20 & 4.26 & 0.23 & 8.19 & 9.81 & 3.59 & 0.28 & 3.55 & 3.59 & 46.50 & 53.50 \\
Louisiana & 1.82 & 1.51 & 2.25 & 6.55 & 0.15 & 25.64 & 57.73 & 0.49 & 2.05 & 2.91 & 0.49 & 64.60 & 35.40 \\
West Texas & 1.11 & 0.89 & 1.23 & 16.00 & 0.06 & 141.67 & 174.67 & 0.24 & 4.11 & 12.98 & 0.24 & 52.70 & 47.30 \\
\hline
\end{tabular}


(a)

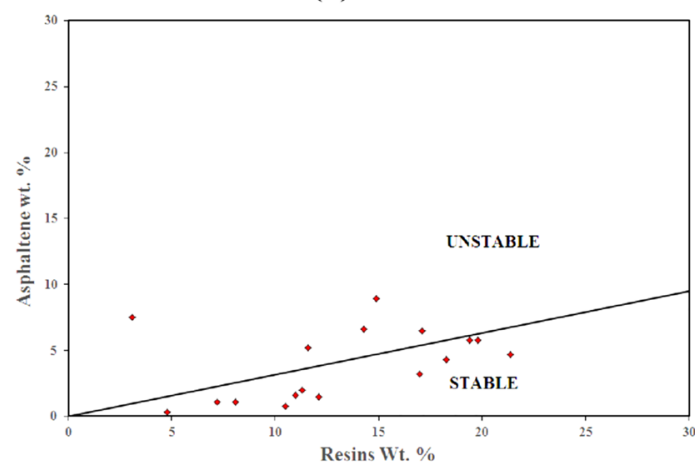

(c)

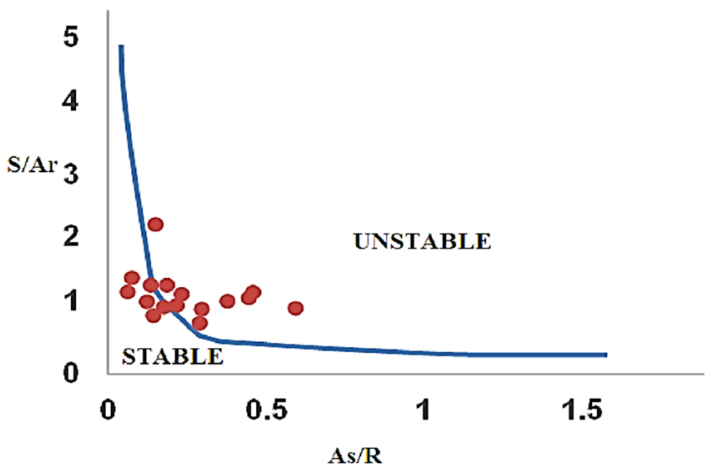

(e)

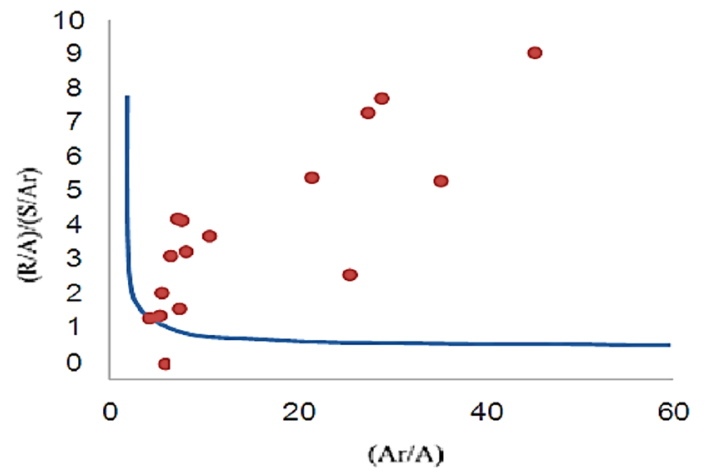

(g)

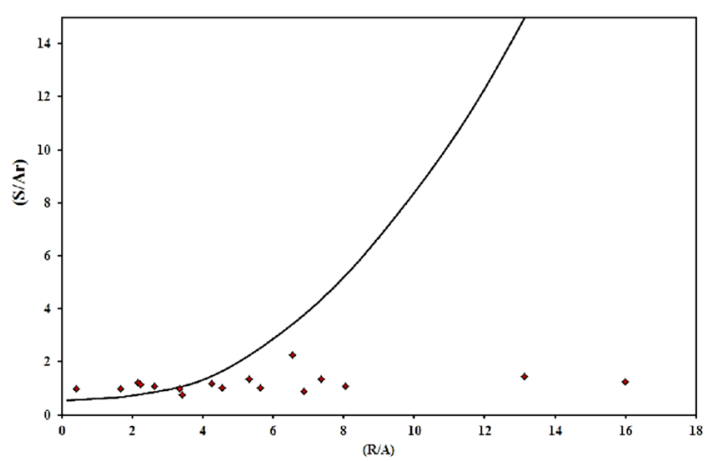

(b)

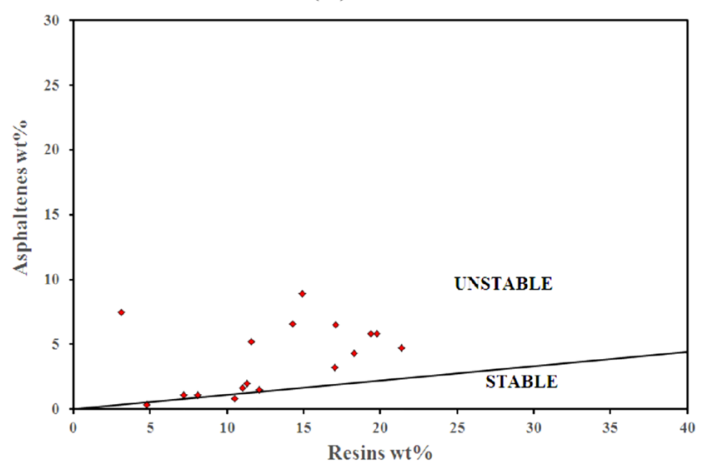

(d)

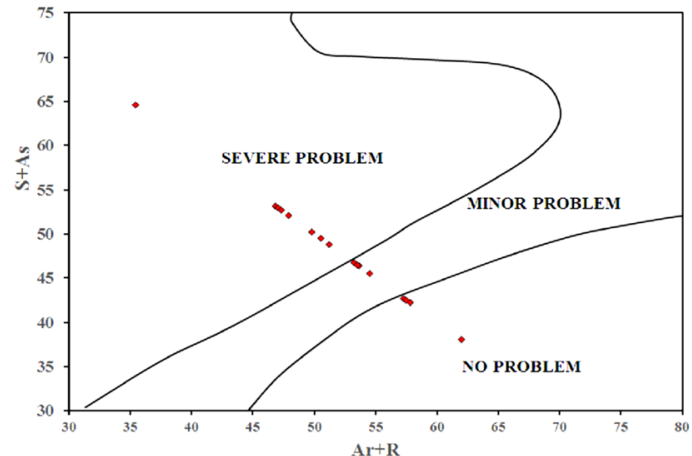

(f)

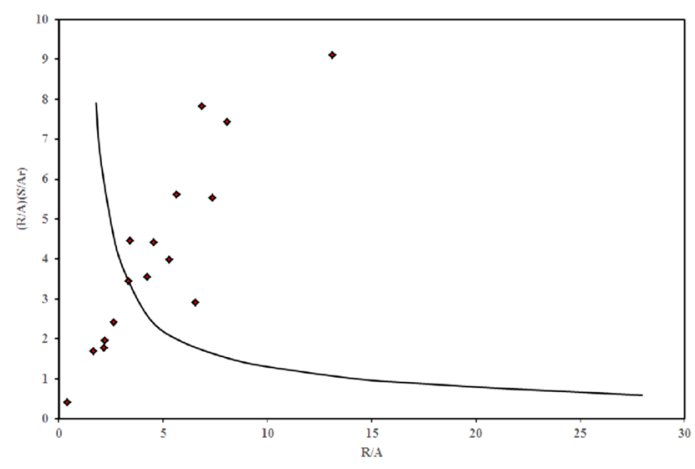

(h)

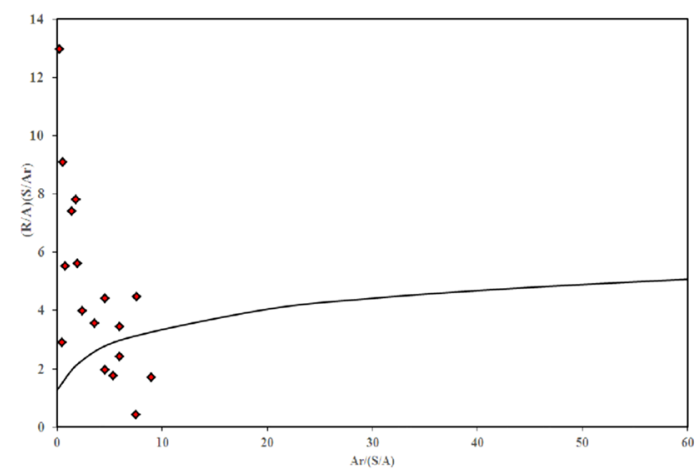

Fig. 8 Showing the results formed by a Jamaluddin, b Modified Jamaluddin, c Stankiewicz plot, d Chamkalani Stability Classifier, e-h Stability Cross Plot, and $\mathbf{i}-\mathbf{n}$ Qualitative-Quantitative Analysis when implemented to 17 crude oil samples 
(i)

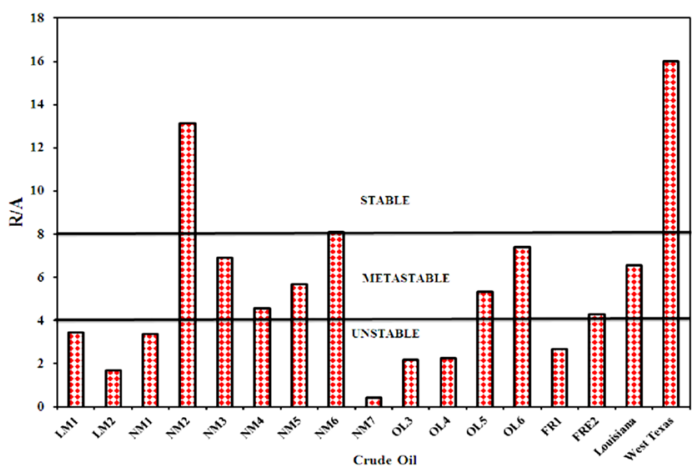

(k)

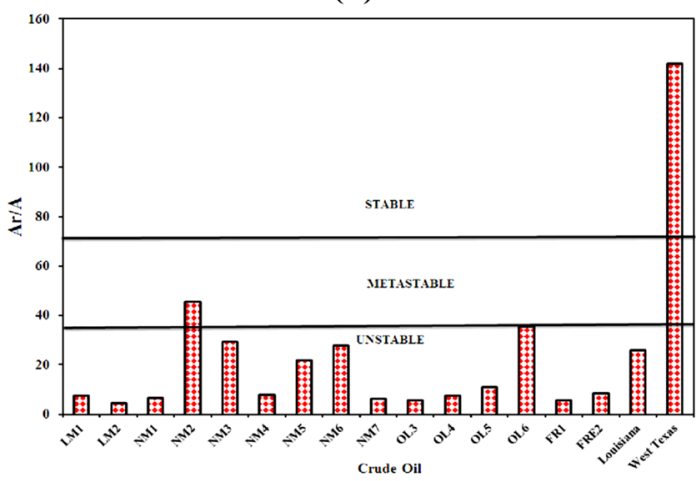

(m)

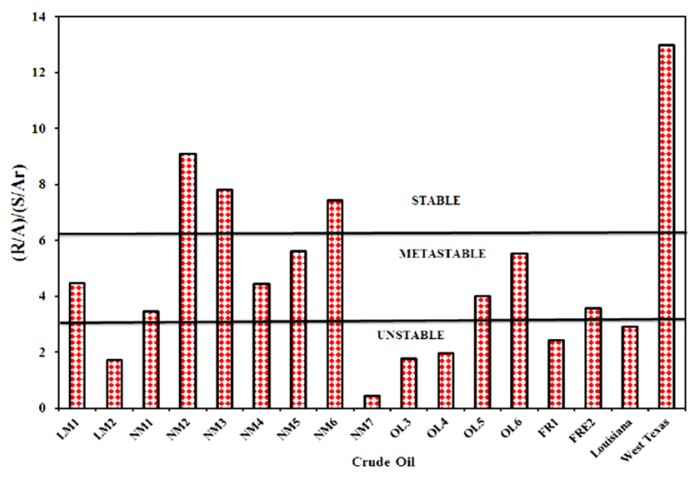

(j)

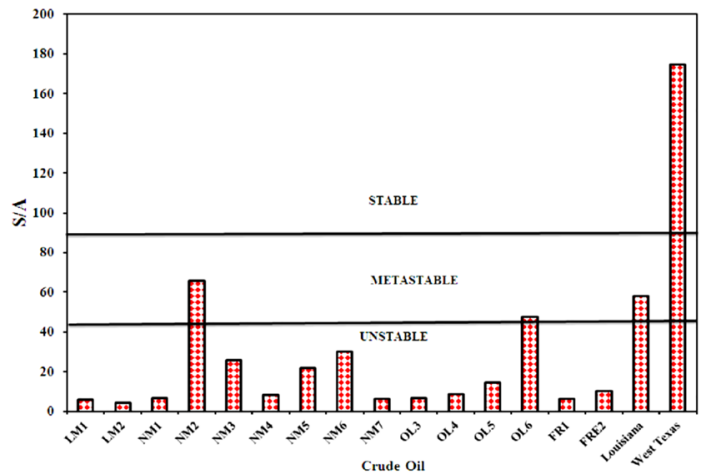

(I)

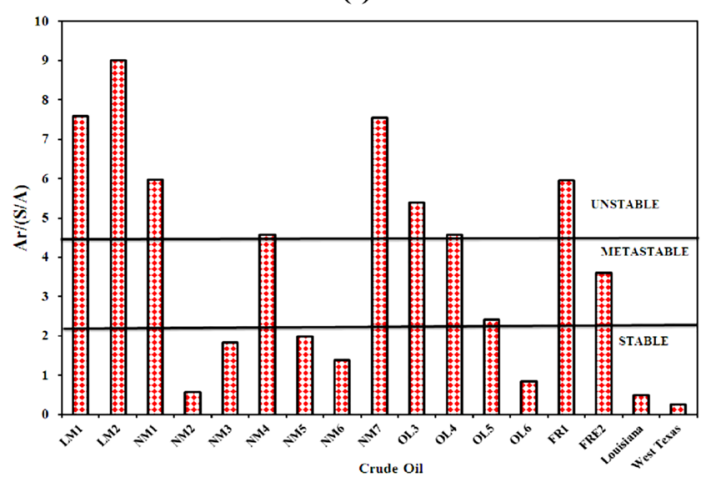

(n)

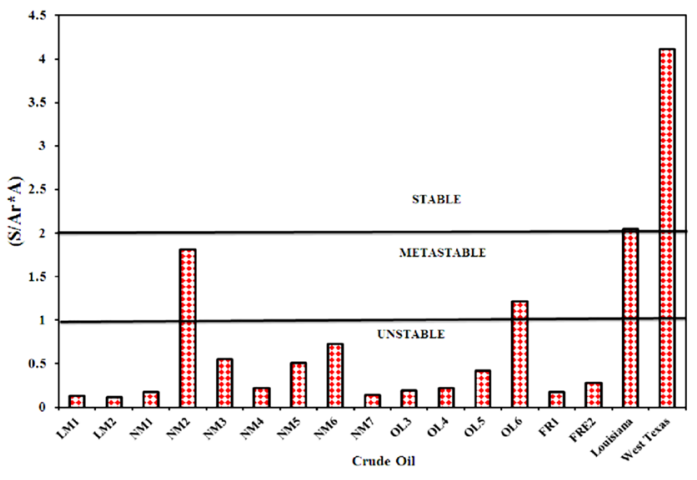

Fig. 8 (continued)

of the oil samples are identified as unstable or uncertain, in terms of asphaltene stability, by these two predicting models. Only one sample, namely; LM1 is correctly predicted as stable sample by CII and CSC. CSI performed best among all predicting models applied. It produces 14 correct predictions out of total 17 predictions made. Like CII and CSC, Stability index (SI) and Jamaluddin's plot (Jamal) yield exactly same predictions. Both predicting models classified six (6) stable samples correctly out of total 8 stable samples in a dataset, while only three unstable samples are accurately identified from the total of 9 unstable samples present in a dataset. Modified
Jamaluddin's plot (Mod. Jamal) identified almost all samples as unstable except two (NM2 and West Texas oil samples) which were found to be incorrect. According to the Stankiewicz plot (SP), four unstable and three stable oil samples are correctly predicted. QQA also yielded somewhat similar results to that produced by SP, however, the predicting model, QQA, predicted some oil samples as metastable. Only four unstable samples and one stable sample are correctly predicted by QQA model. Lastly, SCP predicting model classified six stable samples and three unstable samples correctly. Only one oil sample, namely; NM1 is predicted as Metastable sample by SCP model. 
Table 2 Predicting results of different models

\begin{tabular}{lllllllllll}
\hline Crude oil & $\begin{array}{l}\text { Field } \\
\text { experi- } \\
\text { ence }\end{array}$ & CII & CSI & SI & Jamal & Mod. Jamal & SP & QQA & SCP & CSC \\
\hline LM1 & S & S & S & S & S & U & U & U & S & S \\
LM2 & S & UC & S & U & U & U & U & U & U & UC \\
NM1 & U & UC & U & S & S & U & U & U & MS & UC \\
NM2 & U & U & S & S & S & S & S & S & S & U \\
NM3 & S & UC & S & S & S & U & S & MS & S & UC \\
NM4 & S & UC & S & S & S & U & U & U & S & UC \\
NM5 & $\mathrm{S}$ & $\mathrm{UC}$ & $\mathrm{S}$ & $\mathrm{S}$ & $\mathrm{S}$ & $\mathrm{U}$ & $\mathrm{S}$ & $\mathrm{MS}$ & $\mathrm{S}$ & $\mathrm{UC}$ \\
NM6 & $\mathrm{S}$ & $\mathrm{UC}$ & $\mathrm{S}$ & $\mathrm{S}$ & $\mathrm{S}$ & $\mathrm{U}$ & $\mathrm{S}$ & $\mathrm{S}$ & $\mathrm{S}$ & $\mathrm{UC}$ \\
NM7 & $\mathrm{S}$ & $\mathrm{U}$ & $\mathrm{U}$ & $\mathrm{U}$ & $\mathrm{U}$ & $\mathrm{U}$ & $\mathrm{U}$ & $\mathrm{U}$ & $\mathrm{U}$ & $\mathrm{U}$ \\
OL3 & $\mathrm{U}$ & $\mathrm{U}$ & $\mathrm{U}$ & $\mathrm{U}$ & $\mathrm{U}$ & $\mathrm{U}$ & $\mathrm{U}$ & $\mathrm{U}$ & $\mathrm{U}$ & $\mathrm{U}$ \\
OL4 & $\mathrm{U}$ & $\mathrm{U}$ & $\mathrm{U}$ & $\mathrm{U}$ & $\mathrm{U}$ & $\mathrm{U}$ & $\mathrm{U}$ & $\mathrm{U}$ & $\mathrm{U}$ & $\mathrm{U}$ \\
OL5 & $\mathrm{U}$ & $\mathrm{U}$ & $\mathrm{U}$ & $\mathrm{S}$ & $\mathrm{S}$ & $\mathrm{U}$ & $\mathrm{S}$ & $\mathrm{MS}$ & $\mathrm{S}$ & $\mathrm{U}$ \\
OL6 & $\mathrm{U}$ & $\mathrm{U}$ & $\mathrm{U}$ & $\mathrm{S}$ & $\mathrm{S}$ & $\mathrm{U}$ & $\mathrm{S}$ & $\mathrm{S}$ & $\mathrm{S}$ & $\mathrm{U}$ \\
FR1 & $\mathrm{U}$ & $\mathrm{UC}$ & $\mathrm{U}$ & $\mathrm{U}$ & $\mathrm{U}$ & $\mathrm{U}$ & $\mathrm{U}$ & $\mathrm{U}$ & $\mathrm{U}$ & $\mathrm{UC}$ \\
FRE2 & $\mathrm{S}$ & $\mathrm{UC}$ & $\mathrm{S}$ & $\mathrm{S}$ & $\mathrm{S}$ & $\mathrm{U}$ & $\mathrm{U}$ & $\mathrm{MS}$ & $\mathrm{S}$ & $\mathrm{UC}$ \\
Louisiana & $\mathrm{U}$ & $\mathrm{U}$ & $\mathrm{U}$ & $\mathrm{S}$ & $\mathrm{S}$ & $\mathrm{U}$ & $\mathrm{S}$ & $\mathrm{MS}$ & $\mathrm{S}$ & $\mathrm{U}$ \\
West Texas & $\mathrm{U}$ & $\mathrm{U}$ & $\mathrm{S}$ & $\mathrm{S}$ & $\mathrm{S}$ & $\mathrm{S}$ & $\mathrm{S}$ & $\mathrm{S}$ & $\mathrm{S}$ & $\mathrm{U}$ \\
\hline
\end{tabular}

Where "U" for Unstable, "S" for Stable, "UC" for Uncertain and "MS" for Metastable
In addition, looking at Table 2 it can be clearly observed that NM2, LM2, NM7 and West Texas oil samples are wrongly predicted while three oil samples i.e., OL3, OL4, and FR1 are accurately predicted by most of the asphaltene stability predicting models applied. As discussed in earlier section, that these asphaltene stability predicting models work on the net effect of SARA values; therefore, NM2 and West Texas crude oil, having exceptionally low asphaltene contents, are expected to exhibit good stability in crude oil but in actual conditions, oils show instability towards asphaltene. This case is similar to previously reported cases available in the published literature. For example the Boscan crude oil is found to be operationally stable despite having higher percentage of asphaltene contents in crude oil of approximately 17 percent, while other lighter Arabian oil samples containing very low asphaltene contents exhibit strong instability in field conditions (Law et al. 2019). NM7 crude oil sample is anticipated to be predicted as unstable oil sample but is wrongly predicted by all predicting models applied in this research study. This happens because NM7 possesses low resins and high asphaltene contents. LM2 is another crude oil which was also predicted incorrectly by most predicting models as unstable sample because of its high asphaltene contents. Three unstable oil samples, namely; OL3, OL4 and FR1 are predicted correctly by almost all applied predicting models, whereas none of the stable samples are classified correctly by the predicting models at the same time.
To evaluate the performance metrics for all applied asphaltene stability predicting models, the uncertain and metastable cases are considered as unstable case. This assumption is made because it is better to consider all those oils as unstable which are having incomplete stability information, and therefore, accordingly arrangements for the prevention of asphaltene precipitation are implemented for these oils. Secondly, it was reported in previous research studies that most of the SARA based stability predicting models are inclined towards predicting the oil samples as unstable (Guzmán et al. 2017; Ali et al. 2021a). According to Table 3, CSI proved to be most accurate model in predicting stability of asphaltene in oil as it is quite evident from its comparatively high accuracy. The higher value of TPR, TNR, PPV and NPV of CSI model shows that it predicted both stable and unstable oil samples well. However, it can be seen from its NPV value that instability is slightly better predicted as compared to stability by CSI. CII, CSC and SCP acquire second rank in terms of accuracy. CII and CSC yielded exactly same stability predictions and thus their all statistical metrics calculated are found to be same. Lower TPR and higher TNR values show that these all models predicted unstable samples with high accuracy as compared to stable oil samples. Moreover, their higher PPV value and lower NPV value depict that majority of unstable oil samples are not wrongly predicted but most of the stable oil samples are incorrectly identified, respectively. On the other hand, SCP model predicted stability well as compared to 
Table 3 Values of Statistical metrics calculated for all applied predicting models

\begin{tabular}{llllllllll}
\hline & TP & TN & FP & FN & TPR & TNR & PPV & NPV & ACC \\
\hline CII & 1 & 9 & 0 & 7 & 0.13 & 1 & 1 & 0.56 & 0.59 \\
CSI & 7 & 7 & 2 & 1 & 0.88 & 0.78 & 0.78 & 0.88 & 0.82 \\
CSC & 1 & 9 & 0 & 7 & 0.13 & 1 & 1 & 0.56 & 0.59 \\
SI & 6 & 3 & 6 & 2 & 0.75 & 0.33 & 0.50 & 0.60 & 0.53 \\
Jamal & 6 & 3 & 6 & 2 & 0.75 & 0.33 & 0.50 & 0.60 & 0.53 \\
Mod. Jamal & 0 & 7 & 2 & 8 & 0 & 0.78 & 0 & 0.47 & 0.41 \\
SP & 3 & 4 & 5 & 5 & 0.38 & 0.44 & 0.38 & 0.44 & 0.41 \\
QQA & 1 & 6 & 3 & 7 & 0.13 & 0.67 & 0.25 & 0.46 & 0.41 \\
SCP & 6 & 4 & 5 & 2 & 0.75 & 0.44 & 0.55 & 0.67 & 0.59 \\
\hline
\end{tabular}

instability as depicted from its higher TPR value than TNR value. Lower PPV value relative to NPV value of SCP model suggests that more unstable samples are falsely classified as compared to stable oil samples. Stability index (SI) and Jamaluddin's plot (JP) hold third rank among all predicting models. Similar to SCP model, these predicting models also predict stable samples better as compared to unstable samples as revealed by their higher TPR and lower TNR values. Furthermore, these predicting models also possess higher NPV than PPV values because they predicted more unstable samples incorrectly as compared to stable oil samples. Lastly, at fourth position, Mod Jamal, SP and QQA are placed. All these predicting models identified unstable samples better as compared to stable samples as it is evident from their lower TPR value than TNR value. These predicting models also predicted majority of the stable samples as unstable samples.

The observation found in this study about stability predicting models that CII, SP, CSI, CSC, Mod. JP, QQA are good instability predicting model, while JP, SI and SCP are better stability predicting models are found in strong consensus with the previous research findings reported in the literature (Guzmán et al. 2017; Ali et al. 2021a, b; Pereira et al. 2017). Finally, the sequence of accuracy of these stability predicting models can be written as: CSI > CII, SCP, CSC > JP, SI > Mod. JP, QQA, SP.

This research study proved that each predicting model favors a certain class of crude oils (stable and unstable), except CSI, and therefore affects their prediction accuracies. As far as CSI is concerned, although this predicting model is performed comparatively better but it takes an advantage of dielectric constant values present in its formula. The SARA dielectric values to be placed in the formula for judging the asphaltene stability in crude oil are decided on the basis of prior information about stability status of crude oils. This practice tends this predicting model to perform excellently. Moreover, all SARA-based asphaltene stability predicting models take SARA values as inputs for stability evaluation. These SARA values of crude oils can be determined by variety of techniques and methodologies. The SARA value determined from different techniques could show significant difference in values for the same oil, therefore, may result in inaccurate stability predictions from these models (Pereira et al. 2017; Kharrat et al. 2007; Fan et al. 2002). Furthermore, these predicting models do not take into account the factors like operational parameters such as pressure and temperature, solubility parameter of crude oil and asphaltene, polarities of resins and asphaltenes and compositional and structural characteristics of asphaltene molecule which according to previous studies play a major role in deciding the asphaltenes stability in crude oil (Gharbi et al. 2017; Guzmán et al. 2017; Ali et al. 2021b; Punase et al. 2016; Prakoso et al. 2015, 2018; Goual and Firoozabadi 2002; Hascakir 2017; Asomaning 2003). Finally, the collection point for the testing of crude oil is also important because these SARA values may differ with respect to location due to the compositional changes occurring in crude oil during production. Therefore, it is recommended, to use SARA based models for stability screening in dead crude oil systems working at ambient conditions such as in separators or in downstream operations where operational parameters variations are comparatively low, as compared to upstream crude oil productions, causing less compositional changes in fluids.

\section{Development of new predictor (ANJIS Asphaltene stability predicting model)}

By taking the advantage of CSI excellent accuracy, an attempt is made to develop a reliable generalized stability predicting model, namely; [Abdus, Nimra, Javed, Imran \& Shaine (ANJIS) Asphaltene stability predicting model] by taking the relationship of SARA mentioned in Eq. (8). $k_{1}, k_{2}$, $k_{3}$ and $k_{4}$ are the adjustable parameters found by tuning them through MATLAB optimization tool against CSI outcomes.

ANJIS $=\frac{\left(\mathrm{Sat}^{k_{1}}\right)+\left(\mathrm{As}^{k_{2}}\right)}{\left(\mathrm{Ar}^{k_{3}}\right)+\left(R^{k_{4}}\right)}$ 
After tuning process, the final Eq. (9) of a new predictor Asphaltene stability predictor (ANJIS) is found to be as:

ANJIS $=\frac{\left(\operatorname{Sat}^{1.7269}\right)+\left(\mathrm{As}^{5.186}\right)}{\left(\operatorname{Ar}^{1.525}\right)+\left(R^{4.302}\right)}$

This new model can be applied without having prior knowledge of crude oil stability status. If ANJIS $<0.03$, then oil is classified as stable, while if ANJIS $\geq 0.03$ then oil is identified as unstable.

ANJIS is capable of giving reliable prediction rates both for stable and unstable oil samples. Table 4 shows the prediction results of ANJIS when applied on SARA dataset of 17 crude oil samples used in this study. Although, the accuracy of ANJIS is not extraordinary high, this is quite obvious because of the other factors involved in the stability process of asphaltene other than SARA values. However, the prediction made by ANJIS is quite balanced in terms of identifying both two classes i.e., stability and instability. The other benefit of using ANJIS is that it does not categorized oil samples as metastable or uncertain which other predicting models do. Among all predictors, ANJIS rank second.

It is discussed earlier that predictor fails at certain conditions of SARA values, therefore ANJIS accuracy of 0.76 is good (Table 4).

For further verification of the reliability of new model (ANJIS), the model is applied on one more dataset of Rogel et al. study (Rogel et al. 2003). The SARA dataset with operational stability experience information of 16 crude oils belong to Rogel et al. (2003) study is presented in Table 5.

To compare the performance of ANJIS model with other predicting models, we are referring here to the study of Ali et al. (2021a). Ali and coworkers (Ali et al. 2021a) performed detailed statistical analysis of different SARA based predicting models on the Rogel et al. dataset using 15 crude oil samples. Except CSI, none of the model was able to perform excellently. The second rank models were found to be CII and CSC having accuracy of 0.67 with TNR and TPR value of 1 and 0.28 , respectively, thus showing that these models only predicted unstable stable with high accuracy and poor predictors of stable samples. On the other hand, if the performance of ANJIS is observed, the predicting model has higher accuracy with balance prediction rates for both stable and unstable samples. Table 6 shows the statistical results of ANJIS for Rogel et al. dataset.
Table 5 SARA value of crude oils and their stability status reported by Rogel et al. (2003)

\begin{tabular}{lllrll}
\hline Crude oil & Sat (wt.\%) & $\operatorname{Ar}(w t . \%)$ & R (wt.\%) & As (wt.\%) & $\begin{array}{l}\text { Operational } \\
\text { experience }\end{array}$ \\
\hline U2 & 43.21 & 35.3 & 16.68 & 4.99 & Unstable \\
U16 & 45.31 & 33.29 & 17.55 & 3.85 & Unstable \\
U94 & 49.43 & 37.62 & 8.61 & 4.43 & Unstable \\
U16L & 49.68 & 37.78 & 9.28 & 3.34 & Unstable \\
U91 & 48.61 & 34.35 & 11.65 & 5.38 & Unstable \\
U98 & 48.83 & 37.4 & 9.51 & 4.26 & Unstable \\
U100 & 54.54 & 35.35 & 8.23 & 1.87 & Unstable \\
U103 & 55.41 & 36.77 & 6.89 & 0.94 & Unstable \\
S4 & 49.41 & 38.23 & 10.44 & 1.92 & Stable \\
S29 & 39.62 & 38.71 & 16.83 & 4.93 & Stable \\
S27 & 42.94 & 36.35 & 12.96 & 7.74 & Stable \\
S24S & 49.53 & 41.33 & 2.54 & 6.15 & Stable \\
S23 & 51.79 & 29.93 & 15.83 & 2.46 & Stable \\
S22 & 54.73 & 30.41 & 12.78 & 2.08 & Stable \\
S20 & 32.45 & 41.5 & 21.12 & 4.93 & Stable \\
S277 & 26.13 & 45.3 & 22.57 & 6.01 & Stable \\
\hline
\end{tabular}

\section{Conclusions}

1. All predicting models are easy to apply but showed low accuracies in predicting asphaltene stability in crude oils except CSI.

2. CII, SP, CSI, Chamkalani, Mod. JP, QQA predicted unstable oil samples better, while JP, SI and SCP identified stable oil samples more accurately. This factor tends models to make imbalanced predictions for the two classes of oil samples.

3. CSI performed comparatively better because of the placement of SARA dielectric constants in its formula depending on the oil stability status of field conditions.

4. SARA based models only consider net effect of SARA values, while predicting asphaltene stability and ignores variety of other factors which could impact asphaltene stability in oil thus causing risk of producing erroneous prediction results.

5. A new predictor, ANJIS Asphaltene stability predictor is introduced that can predict both stable and unstable crude oil samples with reasonable accuracy.

6. It is recommended to develop a rigorous model that could incorporate the structural and compositional features of SARA in addition to their weight percentages
Table 4 Values of Statistical metrics calculated for ANJIS model

\begin{tabular}{llllllllll}
\hline & TP & TN & FP & FN & TPR & TNR & PPV & NPV & ACC \\
\hline ANJIS & 6 & 7 & 2 & 2 & 0.75 & 0.78 & 0.75 & 0.78 & 0.76 \\
\hline
\end{tabular}


Table 6 Values of Statistical metrics calculated for ANJIS model on Rogel et al. SARA Dataset (Rogel et al. 2003)

\begin{tabular}{llllllllll}
\hline & TP & TN & FP & FN & TPR & TNR & PPV & NPV & ACC \\
\hline ANJIS & 5 & 6 & 2 & 3 & 0.63 & 0.75 & 0.71 & 0.67 & 0.69 \\
\hline
\end{tabular}

in crude oil along with the operational parameters like temperature and pressure to increase the accuracy of stability prediction. Therefore, ANJIS model may be incorporated in future simulation studies.

Funding There is no funding involved in this research work.

\section{Declarations}

Conflict of interest The authors declare that they have no conflict of interest.

Open Access This article is licensed under a Creative Commons Attribution 4.0 International License, which permits use, sharing, adaptation, distribution and reproduction in any medium or format, as long as you give appropriate credit to the original author(s) and the source, provide a link to the Creative Commons licence, and indicate if changes were made. The images or other third party material in this article are included in the article's Creative Commons licence, unless indicated otherwise in a credit line to the material. If material is not included in the article's Creative Commons licence and your intended use is not permitted by statutory regulation or exceeds the permitted use, you will need to obtain permission directly from the copyright holder. To view a copy of this licence, visit http://creativecommons.org/licenses/by/4.0/.

\section{References}

Ali SI, Lalji SM, Haneef J, Khan MA, Louis C (2021a) Comprehensive analysis of asphaltene stability predictors under different conditions. Pet Chem 61(4):446

Ali SI, Lalji SM, Haneef J, Ahsan U, Tariq SM, Tirmizi ST, Shamim $\mathrm{R}$ (2021b) Critical analysis of different techniques used to screen asphaltene stability in crude oils. Fuel 299:120874

Alimohammadi S, Zendehboudi S, James L (2019) A comprehensive review of asphaltene deposition in petroleum reservoirs: theory, challenges, and tips. Fuel 252:753-791

Al-Qasim A, Al-Anazi A, Omar AB, Ghamdi M (2018) Asphaltene precipitation: a review on remediation techniques and prevention strategies. In: Abu Dhabi international petroleum exhibition \& conference held in Abu Dhabi, UAE, 12-15 November 2018. SPE-192784-MS

Ashoori S, Sharifi M, Masoumi M, Salehi MM (2017) The relationship between SARA fractions and crude oil stability. Egypt J Pet 26:209-213

Asomaning S (2003) Test methods for determining asphaltene stability in crude oils. Pet Sci Technol 21:581-590

Bekkar M, Djemaa HK, Alitouche TA (2013) Evaluation measures for models assessment over imbalanced data sets. J Inf Eng Appl 3

Boussingault JB (1837) Mémoire sur la composition des bitumes. Ann Chim Phys 64:141-151
Chamkalani A (2015) Application of LS-SVM classifier to determine stability state of asphaltene in oilfields by utilizing SARA fractions. Pet Sci Technol 33(1):31-38

Fakher S, Ahdaya M, Elturki M, Imqam A (2020) Critical review of asphaltene properties and factors impacting its stability in crude oil. J Pet Explor Prod Technol 10:1183-1200

Fan T, Wang J, Buckley JS (2002) Evaluating crude oils by SARA analysis. In: SPE/DOE improved oil recovery symposium. SPE 75228

Gharbi K, Benyounes K, Khodja M (2017) Removal and prevention of asphaltene deposition during oil production: a literature review. J Petrol Sci Eng 158:351-360

Goual L (2012) Petroleum asphaltenes, crude oil emulsions-composition stability and characterization. Intechopen, London

Goual L, Firoozabadi A (2002) Measuring asphaltenes and resins, and dipole moment in petroleum fluids. AIChE J 48:2646-2663

Guzmán R, Ancheyta J, Trejo F, Rodriguez S (2017) Methods for determining asphaltene stability in crude oils. Fuel 188:530-543

Hascakir B (2017) A new approach to determine asphaltene stability. In: SPE annual technical conference and exhibition, San Antonio, Texas, USA. SPE-187278-MS

Kharrat AM, Zacharia J, Cherian VJ, Anyatonwu A (2007) Issues with comparing SARA methodologies. Energy Fuels 21:3618-3621

Law JC, Headen TF, Jiménez-Serratos G, Boek ES, Murgich J, Müller EA (2019) Catalogue of plausible molecular models for the molecular dynamics of asphaltenes and resins obtained from quantitative molecular representation. Energy Fuels 33:9779-9795

Leon O, Contreras E, Rogel E, Dambakli G, Acevedo S, Carbognani L, Espidel J (2002) Adsorption of native resins on asphaltene particles: a correlation between adsorption and activity. Langmuir 18:5106-5112

Madhi M, Kharrat R, Hamoule T (2018) Screening of inhibitors for remediation of asphaltene deposits: experimental and modeling study. Petroleum 4:168-177

Mansoori GA (2010) Remediation of asphaltene and other heavy organic deposits in oil wells and in pipelines. In: Socar proceedings

Melendez-Alvarez AA, Garcia-Bermudes M, Tavakkoli M, Doherty RH, Meng S, Abdallah DS, Vargas FM (2016) On the evaluation of the performance of asphaltene dispersants. Fuel 179:210-220

Mohammed I, Mahmoud M, Al Shehri D, El-Husseiny A, Alade O (2021) Asphaltene precipitation and deposition: a critical review. J Pet Sci Eng 197:107956

Pereira VJ, Setaro LLO, Costa GMN, Vieira de Melo SAB (2017) Evaluation and improvement of screening methods applied to asphaltene precipitation. Energy Fuels 31(4):3380-3391

Prakoso A, Punase A, Rogel E, Ovalles C, Hascakir B (2018) Effect of asphaltene characteristics on its solubility and overall stability. Energy Fuels 32:6482-6487

Prakoso AA, Punase AD, Hascakir B (2015) A mechanistic understanding of asphaltene precipitation from varying saturate concentration perspective. In: Proceedings of the SPE Latin American and Carribean petroleum engineering conference, Quito, Ecuador. SPE-177280-MS

Punase AD, Prakoso AA, Hascakir B (2016) The polarity of crude oil fractions affects the asphaltenes stability. In: Proceedings of the SPE western regional meeting, Anchorage, AK. SPE-180423-MS

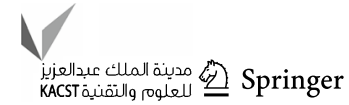


Rogel E, Leon O, Espidel Y, González Y (2001) Asphaltene stability in crude oils. SPE Prod Facil 16(2):24-88

Rogel E, León O, Contreras E, Carbognani L, Torres G, Espidel J, Zambrano A (2003) Assessment of asphaltene stability in crude oils using conventional techniques. Energy Fuels 17(17):1583-1590

Sepúlveda JA, Bonilla JP, Medina Y (2010) Predicción de la estabilidad de los asfaltenos mediante la utilización del análisis SARA para petróleos puros. Rev Ing Reg 7:103

Stankiewicz AB, Flannery MD, Fuex NQ, Broze G, Couch JL, Dubey ST, Iyer SD (2002) Prediction of asphaltene deposition risk in E\&P operations. In: Third International symposium on mechanisms and mitigation of fouling in petroleum and natural gas production, New Orleans: AIChE

Thou S, Ruthammer G, Potsch K (2002) Detection of asphaltenes flocculation onset in a gas condensate system. In: SPE 13th european petroleum conference, Aberdeen, Scotland, U.K., 29-31 October 2002. SPE 78321
Wattana P, Fogler HS, Yen A, García MDC, Carbognani L (2005) Characterization of polarity-based asphaltene subfractions. Energy Fuels 19:101-110

Zendehboudi S, Shafiei A, Bahadori A, James LA, Elkamel A, Lohi A (2014) Asphaltene precipitation and deposition in oil reservoirs -Technical aspects, experimental and hybrid neural network predictive tools. Chem Eng Res Des 92(5):857-875

Zheng F, Shi Q, Vallverdu G, Giusti P, Bouyssière B (2020) Fractionation and characterization of petroleum asphaltene: focus on metalopetroleomics. Processes 8(11):1504

Publisher's Note Springer Nature remains neutral with regard to jurisdictional claims in published maps and institutional affiliations. 